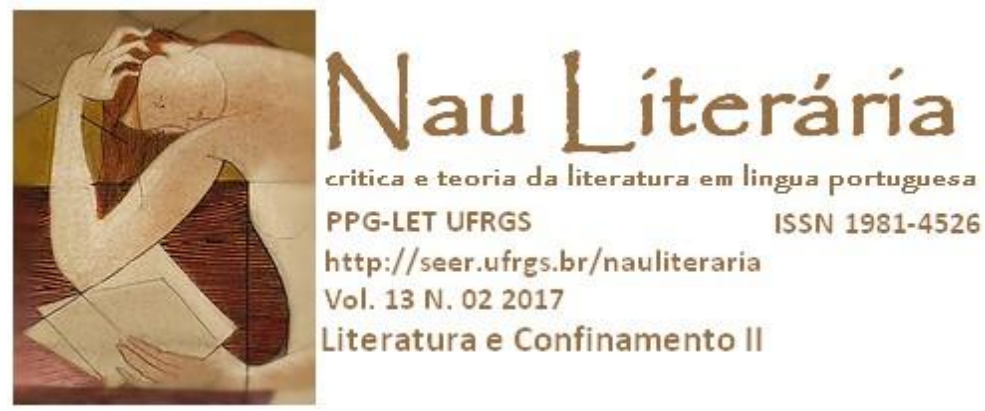

\title{
O verso e o reverso - A. de Campos e Cy Twombly: atuações e respirações, membrana e confinamento
}

\author{
Marcus Alexandre Motta \\ Marcelo Lins Magalhães
}

Resumo: O presente trabalho busca abordar o poema A passagem das Horas, de Álvaro de Campos, segundo a sua repercussão na ambiência plástica da obra sem título ("Em memória de Álvaro de Campos") de Cy Twombly. Tratase aqui de considerar a hipótese de que os versos de Álvaro de Campos captam a materialidade específica da obra de $\mathrm{Cy}$, uma vez que certa expressão de interioridade do poema parece perfazer ou modelar a indeterminada superfície do trabalho plástico. Concomitantemente, a presença da massa plástica da obra $\mathrm{Cy}$ acena para reconciliações com o inacabado do poema, como se este adquirisse a sua "alma" com esta remissão. Em vista destas ponderações, faz-se necessário dizer que a voz de Álvaro talvez só se torne plausível mediante outras vozes que lhe respiram fora do confinamento.

Palavras-chave: Álvaro de Campos; Cy Twombly; membrana

Abstract: The present work attempts to approach the poem The passage of the Hours, by Álvaro de Campos, according to its repercussion in the plastic environment of Cy Twombly`s artwork without title ("In memory of Àlvaro de Campos"). It is a task here of considering the hypothesis that Álvaro de Campos's verses capture the specific materiality of Twombly 's artwork, since a certain expression of interiority of the poem seems to model or shape the unspecified surface of the work of art. Concurrently, the presence of the mass from Twombly`s artwork signs for reconciliations with the unfinished poem, as if it acquires its soul with this remission. In view of these considerations, it is necessary to say that Campos's voice may only become plausible through other voices that breathe him out of the confinement.

Keywords: Álvaro de Campos; Cy Twombly; membrane.

"É indelicado se espantar quando algo é belo ou grande; como se pudesse ser de outra maneira." F. Schlegel 


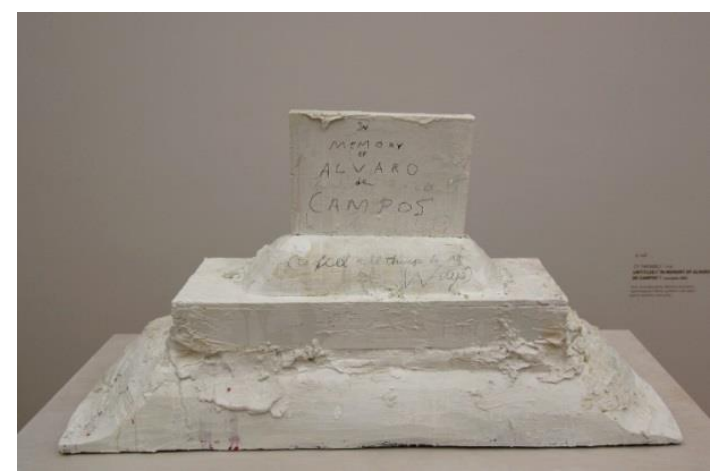

Fig.1- sem título ("Em memória de Álvaro de Campos") de Cy Twombly.

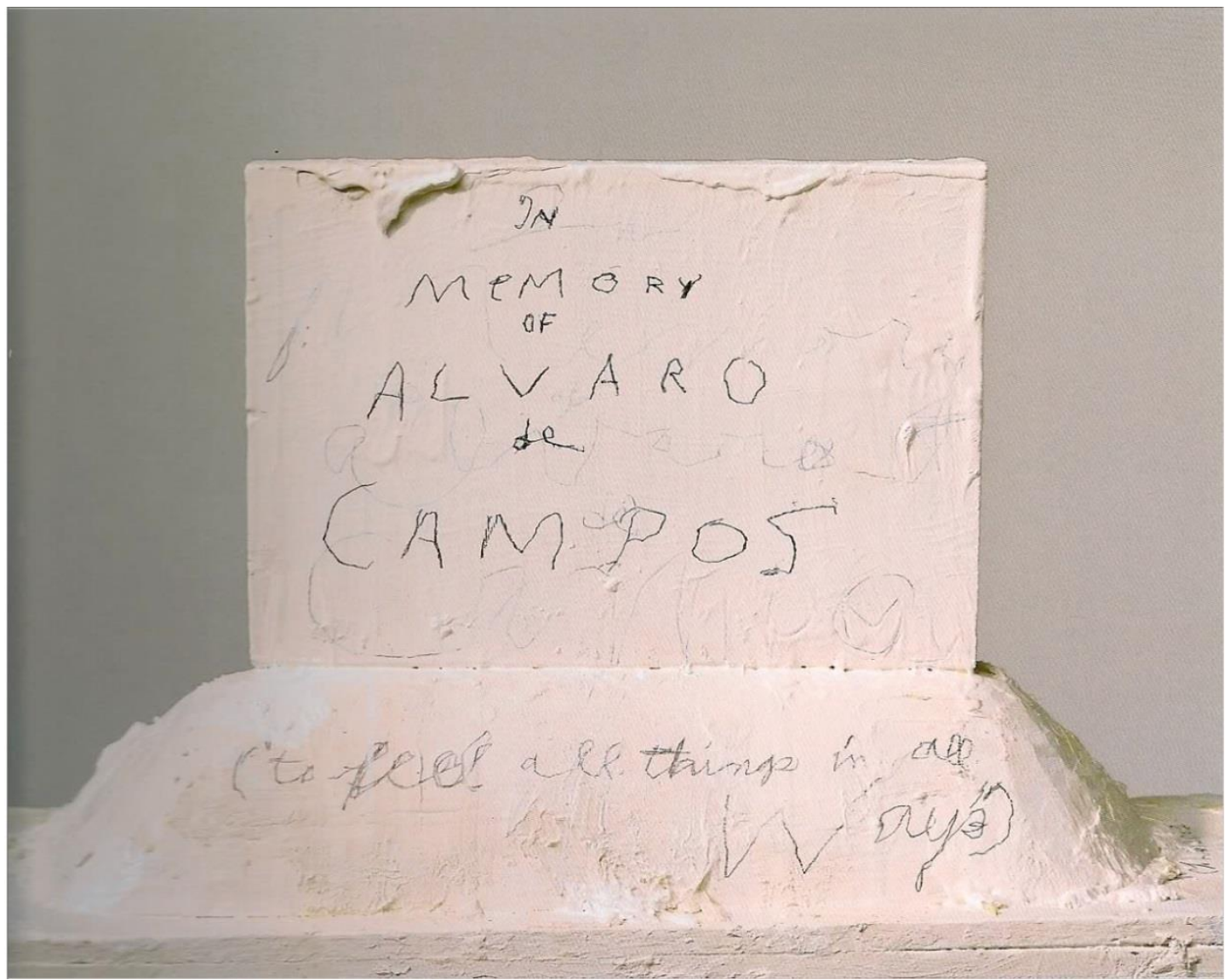

Fig.2 - sem título ("Em memória de Álvaro de Campos") de Cy Twombly, detalhe.

\section{I}

A membrana silenciosa, e a memória, e a massa plástica, e, então, o gesto, sem odores, o dom daquela língua do visível — ritmo escultural. Mas quem? Cy Twombly e Álvaro de Campos. $\mathrm{O}$ último in memoriam (o último?) — de dentro da memória, nela e além dela, ou seja: ela. A massa escorre e se implanta. A tumba. Tumba? Não seria melhor mausoléu? De fato, a sepultura. Há também a lápide. Uma inscrição e outra na sombra da massa. Por fora, o melhor é ficar no 
gerado: Mnemósine à margem do rio - no extremo do vazio que a cerca, na ponta do tempo, silenciosamente. Desde sempre, ele, Álvaro, sugere o pervertido transcendentalismo do extremo, da massa dos versos. Algo, dos poemas seus, assim fica. Soa prová-lo em cada membrana que o respira e a obra Cy capta e já é uma outra coisa e a mesma coisa.

\section{II}

Aqui e ali, à medida que algo de Álvaro é postergado, longe de tornar aceitável qualquer unidade do eu, em reverso também se viabiliza o trabalho de memória. E dele decorre o testemunho de figura interna, isto é, o ressoar além do confinamento dos versos na experiência concreta e íntima de uma obra plástica, que assim justifica a singularidade da poesia. Por aqui, ou por lá, o poema em ato se deixa coincidir com a sedimentação das formas, no presente do trabalho de arte que o acolhe e o anima. Para cá, ou para lá, o dizer de Álvaro segue indefinidamente enquanto pensamento de partida.

Passagens, viagens, experiências, sensíveis só o são quando deslocam. A membrana das massas, a passagem e etc.: da pele gráfica ao manto da memória e vice e versa. Tão espessas que o nome membrana não dá para o gasto e as salva. $\mathrm{O}$ atuar da membrana é o agir da obra $\mathrm{Cy}$, e esse atuar é a realização plástica. Mas é, ao mesmo tempo, o prélio ativo do verso Álvaro.

Toa ser a massa mesma, no seu agir plástico, a incontestabilidade persistente em si e para si. A obra Cy, e seus momentos, surgem como conteúdo de superfície, como forma, desvanecendo em cada um dos seus "andares" como reflexão da arte mesma, cuja suplantação dos momentos é um destinar para outro. Pois sua unidade:

[...] só pode ser concebida como unidade através dos seus momentos; os momentos devem ser distinguidos um do outro se é que eles devem se harmonizar no teor e não serem nem meramente separados, nem passivamente idênticos. (ADORNO, 1992, p. 128).

Como um poema? O todo da obra Cy é a individualidade radical do verso Álvaro, um revés. A abstração materializada, o reverso, com suas estações dissociadas, projeta o verso para fora e o atrai para si.

Obra Cy implementada sai do ponto no qual poderia ser discernida. Reage, mostrando-se no atuar de sua membrana e no atarefar-se com o verso Álvaro. Mas quando se dá conta disso, ela elabora o sono e a visão do seu agir e não ela mesma. Isso não quer dizer que ela engane. Antes patenteia o próprio atuar e atarefar-se, pondo a arte em abalo na estática presença do que é.

Aqui é preciso ponderar acerca do sentido desta dissociação que produz, por fim, o indiscernível "composto poeticamente." (Ibid., p. 112). Antes de se chegar a um termo em 
particular, a massa se evade em desajeitado apuro, considerando a maneira indiscernível como ora lastreia um volume, ora impele um alcance erosivo, ora ergue, ora soçobra, o que solicitaria nossa atenção às suas camadas, bancos e relevos. Nestes costados reside a sugestão de caminhos.

A obra de Cy, portanto, deve aceitar nossas vistas. A visita está por certo silente. Aparição "carnal" de um verso. Um corpo-massa. Um resgate. Um anverso da face da criatura. Um silêncio que diz. Nada mudo. E, então, a obra dele equivale estar entre o constructo material e o "demônio feminal" que entra no sono de quem a vê e copula com ele e rouba sua energia e a deposita ali, aos seus pés. A forma da massa, a obra de Cy, é a calipedia do que declara: "sentir tudo de todas as maneiras." (CAMPOS, 1964, p. 220).

\section{III}

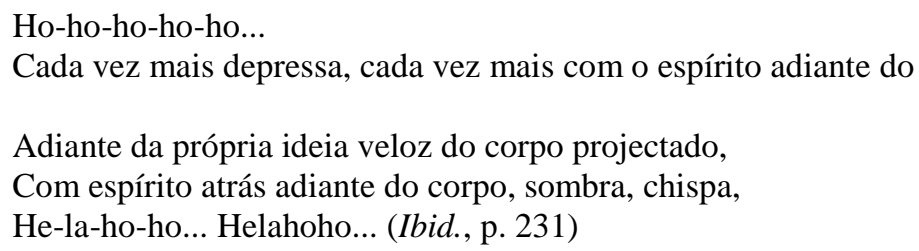

Mas a obra se vê? Como vê-la se, contemporaneamente, a visão já é teoria de engessamento e nega a aspiração de ver? Para a visão o espaço é nada menos do que a integralidade daquilo que ela paralisa e o deixa existir igualmente. Então não se vê? Quase sempre. A obra Cy cria um solapar na visão, um desterro que impede qualquer imperativo comum a ela e faz uso dela contra ela. A inscrição lastreia a audição, in memoriam. Vibração corpórea do verso Álvaro. Verso que são todos os "versos" da arte. A obra de Cy um verso? Com um verso? Um poema? Um anverso? Versura da arte. Escultura audível de insofismável silêncio do reverso.

O som do verso Álvaro é a exterioridade da obra Cy. Surgindo, aniquila-se em virtude do seu estar ali. É mais forte do que a corporeidade que resta e, por isso, modela a expressão da interioridade do lado de fora, ascendendo a interioridade da massa à interioridade mesma, o fora, in memoriam - como se alguém, ali, colocasse a mão no peito que não há, sentindo-se respirar por ali e atentasse para o destino que a obra cumpre e se esquece.

O vazio que aí se coloca fornece ares de uma presença, especificamente espaçada, que conduz o ato de ver enquanto experiência de cesura. De tal modo, que, enquanto apreensão plástica das remissões entre Cy e Álvaro, parece propício que se possa falar em um problema de figurabilidade na massa. Isto é, desprovida de "alguma noção programática da forma" (SMITH apud DIDI-HUBERMAN, 1998. p. 118), a massa não é mais do que parece ser. Constitui antes o nome de qualquer coisa que recua vigorosamente da ênfase representativa pelo material. Isto é, 
inquietantemente a massa faz o visível escorrer, ou transbordar, o que coaduna com toda artisticidade que se coloca às voltas com a estatura de algo que resta. E que assim sendo, põe em retirada a perfeição.

\section{IV}

Nada de puramente mortal, nada impuramente vivo — a indecibilidade ali está. Labores da membrana pesada, versura da massa plástica. — três degraus (três estrofes?), uma cesura (o verso Álvaro), um início, um fim, uma lápide, in memoriam, e a base se esparramando. Do ateliê de Cy? De fato, quando se observa a obra dele, bem nisso, ela preceitua. In memoriam há de ser sentido de todas as maneiras na forma da massa. A obra é isso - todas as maneiras do "teor" arte. Uma declinação, uma instabilidade, uma desinstalação, uma queda da forma (ideia, gestalt, figura, na massa). $\mathrm{O}$ apelo do dom, dessas duas singularidades artísticas em uma, da vinda (quem sabe?) do acontecimento arte. Imperturbabilidade do "inocente" à beira do rio (letal) ou seja: a identidade sem identificação, um cenário. Um cenário, um altar, um túmulo e etc., uma certa maneira ancorada numa descrição falha, sem poder saber de suas ramificações. A obra apresenta, portanto, ser a massa plástica o que deve estar na extremidade de qualquer coisa, mesmo da vida e da morte, e in memoriam. E o verso Álvaro? Também, como precocidade do antes e do depois, a morte e a vida outra vez, e a seguir no vice e versa, - na ponta da fala, do canto, do dizer, do fazer, in memoriam (só há o silêncio). Eles são o mesmo modo, arte. E como só há uma obra, só há face de dois no um, sem plural.

A obra plástica provém da única "figura", arte. Eis a figura que nunca deixa de se desfigurar - há nela, continuamente, a relação com o silêncio, como unidade das vozes ditas, jamais caladas, conforme a escolha de quem se volta, ou dá volta nela, estando às voltas, nas passagens, conforme recomeça o "ler”, plasticamente, na última desfiguração, no máximo dos versos ("sentir tudo de todas as maneiras") —, cujo reverso é a última expectação em decidir dar voltas no silêncio, propondo um giro a mais, uma vez mais, até repartir o estado da imagem e seu destino. No infalível destino de respiração. No modo da contemplação e pronúncia do silêncio. No exato momento da literalidade do silêncio, da mão, seja numa página ou em qualquer suporte. E assim permanece como massa plástica, do verso e não arte. 
Despi-me entreguei-me.

E há em cada canto da minha alma um altar a um deus diferente. (CAMPOS, 1964, p. 221).

\section{$\mathbf{V}$}

A capacidade e a impaciência são errâncias do verso e da escultura - expiações da massa. Capacidade do fazer em si mesmo, impaciência cognitiva. Se na obra de Cy, o verso Álvaro pode sofrer da suas memórias-versos, impropriamente, ela mesma, como massa plástica, é a magnitude física da sensação de outras artes, in memoriam. O ritmo estrutural da membrana (o transporte de massa à massa) é a visão e o sono. Mas na obra nada se vê que não esteja para além e para aquém e ali mesmo, e o sono está antes da morte e até após e ali (ver é uma coisa bastante difícil, já que o nome das coisas assina os seus nomes nos olhos e já não deixa ver). Todo o sono está na massa Cy e no seu verso Álvaro. Quem a vê, de algum jeito, compreende a sua solidão ao despertá-la. É essa solidão que se confunde com a noção de sono e isso consubstancia a reminiscência de ser o espírito da arte aquilo que é descoberto no acordar, um outro ver.

Nada é decidível, portanto. Mesmo numa sepultura? Quando a sepultura se coloca como boca de barco à vela, visto de lado, em retirada, os sentidos, à fria tranquilidade, argenteiam o quando dela já está na partida que não acontece e o sono e a visão cavalgam, um no lugar do outro — numa improcedência sem rastros. Montam no silêncio, dão voltas, se voltando para onde se volta, na cadência desarmônica do cavalgar, o verso, às voltas com o fazer de destino da arte, no reverso da obra Cy. Isso porque tudo ali se volve selado ao que se visa dando voltas por ali. Tudo está no jeito da massa. A inscrição, o verso Álvaro é, inacreditavelmente, uma tremenda massa "sentir tudo de todas as maneiras" - exigindo estar às voltas com a massa da obra Cy. Assistências materiais do descompasso da ideia, de alguma coisa em outra coisa como a mesma coisa, galopando.

\footnotetext{
Ho-ho-ho-ho-ho-ho-ho

Cavalgada alada de mim por cima de todas as coisas,

Cavalgada estalada de mim por baixo de todas as coisas,

Cavalgada alada e estalada de mim por causa de todas as coisas...

Hup-la por cima das árvores, hup-la por baixo dos tanques,

Hup-la contra as paredes, hup-la raspando nos troncos,

Hup-la no ar, hup-la no vento, hup-la, hup-la nas praias,

Numa velocidade crescente, insistente, violenta,

Hup-la hup-la hup-la hup-la... (Ibid., p. 234).
} 
Os "artistas" são massas. Compostos de terras e céus. Apenas quando "vestidos", massa, fazem sinais como (ou com) o verso Álvaro na obra de Cy e vice e versa. Eis a membrana das massas: a pele gráfica e o manto da memória. Ritmos do aceno da matéria. Matéria da espera, da volta, à volta, no não pode ser e poder ser tudo massa. O Álvaro na partida da massa escorrida, de duro colo Cy. Nada se esvai. Acena abeirando-se: na morte não há terrores. Tudo em crua cor. E a arte, no cru da cor e no grafismo de péssima letra, há de descansar enfim. Mas descanso não há, pois, a imobilidade ilude na distração de sua parada.

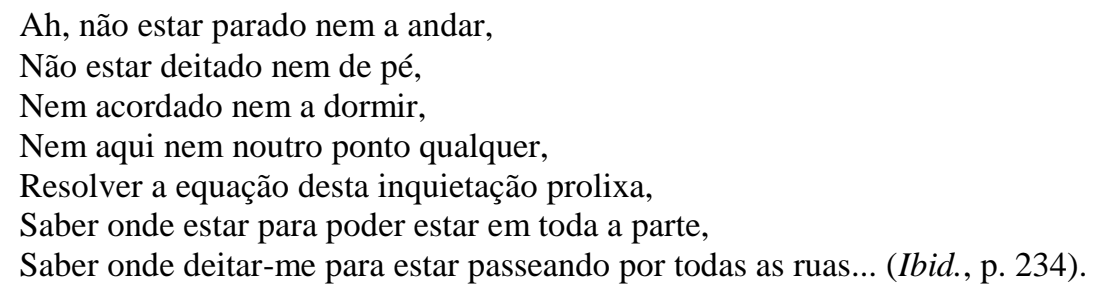

"Saber onde" - no entusiasmo e no desassossego. O falar alto do silêncio, ali na obra $\mathrm{Cy}$, longe de qualquer conceito de arte e de suas necessidades, reside no diálogo como uma extensão abandonada, como profundidade vaga, na medida da extensão de sua membrana, que dispara sua exteriorização e, portanto, vela a própria arte, impropriamente, renunciando em se fazer de mero entendimento - o sono da sabedoria da arte não se deixa ver tão facilmente, pois concebe e produz o que ela é: a natureza oferecida, mortal!

Aliás, não é nada difícil ver o galope no silêncio que acontece ao sono e a visão. Cada um deles rompe com seu ser aí e dos seus correspondentes representar. Seus abalos se revelam por desmanches de um no outro, como algo que se avizinha e se põe num desmoronar gradual que não altera a fisionomia do todo da obra $\mathrm{Cy}$, montados no silêncio como força da verdade. Mas o silêncio é pela metade uma indiferença e de outra um mistério — cumprimento da promessa: só, a morte viverá a vida humana.

\section{VII}

"Meu ser elástico, mola, agulha, trepidação." Inda há tudo isso. Ali, na escultura, e arquitetura, e poema, e música silente, no indistinguível da lápide, do morro, do promontório, do barco de quilha para o ar, da nau insensata que há de rumar parada, sem estar fixa — pois o tempo não é movimento e se faz apenas nele. A obra Cy é o si mesmo da criatura que nela se deita. Um bem-vindo do desfrute do seu impróprio atuar que se acorda ali. Nada se faz de conta, pois a sua 
atuação consolidada é algo só para ela, de onde traz para si a sua presença — um vir a ser da massa plástica mesmo.

Isso diz: a massa exposta é a descoberta do silêncio da membrana que faz a passagem do gráfico para o seu túmulo, e vice e versa, e os põem à "mesa", tratando tudo com algo apenas seu — uma ação plástica transbordante (fica aqui a dúvida se o poema de Álvaro, no qual está o verso da inscrição, não é tal e qual a obra Cy). O atuar singular, portanto, é o agir para outro, atraindo-o e se expondo ao silêncio e sendo o que é silentemente.

Ali, não se perde um minuto dessa estranha aparição, pois "a estranheza se origina em algo objetivo, a extinção do seu conteúdo básico na expressão, a eloquência de algo que não tem linguagem.” (ADORNO, 1992, p. 112). Só há de ver o espantoso no soante verso da obra Cy, para além e aquém de toda prova silenciosa - nada pode existir sem quedar seu conteúdo no silêncio. Ali se deixa descansar os olhos, de baixo para cima e vice-versa, e se conta os degraus. Sem vaidade faz passar o que se segue. Tábua do testemunho - o verso Álvaro. Túmulo do plural — a obra Cy. Aparição é esperada.

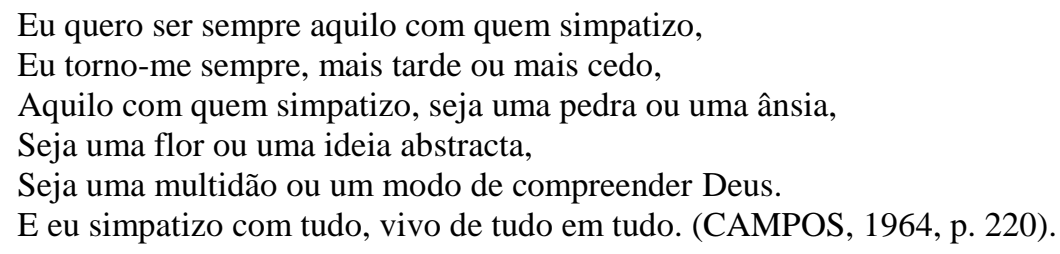

\section{VIII}

O tempo, a nau, o túmulo, o caminho do poço da memória, cuja música silente há de potencializar a voz, mantida na reserva. Eis a pirâmide. Mas não era um túmulo, uma sepultura e etc.? A fonte natural guarda silêncio na voz escutada - um altar. Mas desde quando a voz de Álvaro de Campos deixa de ser a voz de outro? Nunca houve a voz Álvaro que não fosse outras vozes a respirá-la e, ao mesmo tempo, tê-las, lê-las, esculpi-las, cantá-las. A última respiração é a obra de Cy. Última? Nunca há a última porque nunca aconteceu a primeira. Portanto, não há o sem voz na obra Cy. Não há e há. Isso porque a massa da obra Cy já é massa de outras plásticas. E mesmo de outras sem canto, sem posse, sem canto e leitura, sem respiração e etc. O verso é o reverso, não é?

Foram dados na minha boca os beijos de todos os encontros, Acenaram no meu coração os lenços de todas as despedidas, Todos os chamamentos obscenos de gestos e olhares Batem-me em cheio em todo o corpo com sede nos centros sexuais. 
Fui todos os ascetas, todos os postos-de-parte, todos os como que esquecidos,

E todos os pederastas — absolutamente todos (não faltou nenhum).

Rendez-vous a vermelho e negro no fundo-inferno da minha alma! (Ibid., p. 222).

Mas isso nem furta e nem assassina. Nos seus atos o que se altera é o que não se torna condizente com um gesto de linguagem esperado. Os traços da obra Cy espalham o que se visa de algo arte e não imediatamente o que são. Oferecem-se logo à inteligência como constelações plásticas, porque há nelas a determinidade do diverso, pois este não lhe concerne peculiarmente. Tomada de si, é, portanto, a coisa da arte, tão indiferente quanto à morte, sendo visada na estrutura do que é, carregando nela a mímica do outro, no "deitar" de algo artisticamente imediato — um lugar.

\section{IX}

O "mar" acontece. Bate no primeiro degrau e as ondas se seguram no promontório e, sobre ele, um outro volume, talvez um monumento, no qual a inscrição do verso se dá. Enterrada está a lápide, in memoriam. A morte não se achega. Ela está ali paralisada. É ela que protege Álvaro de Campos de morrer. Entre o substantivo e o verbo muitos descompassos se fixam. Talvez esteja ali, a morte, como expressão no gesto de escape de si mesma. A morte não há de morrer. Mas tudo morre. Morre em Álvaro de Campos e nada morre no morrer e não deixa de morrer e a morte deixa de chegar e a obra de Cy surge. Quem é o quê? A arte.

Viver tudo de todos os lados,

Ser a mesma coisa de todos os modos possíveis ao mesmo tempo,

Realizar em si toda a humanidade de todos os momentos

Num só momento difuso, profuso, completo e longínquo. (Ibid., p. 220).

No entanto, a obra parece introduzir a diferença da sua natureza originária, sendo algo determinado, do mesmo modo que a natureza originária se exprime: morte! Com efeito, ao ser deixada em liberdade pelo atuar, como efetividade essencialmente negativa, ela, a obra Cy, se qualifica. Num confronto com ela mesma. Então, é possível compará-la com o verso Álvaro que já está lá, abrangendo as diferenças artísticas no abarcar da mais forte energia da natureza dos mortais e possuindo-a de maneira mais artística ainda. Portanto, não há cabimento na exaltação, na lamentação. Seja o que for que a obra Cy faça, ou que lhe aconteça, foi ela quem fez, e isso é ela: uma obra da massa artística que traslada o si mesmo da morte numa eficácia do dia da presença - o que vem a seu encontro na presença do dia é o mesmo que jazia no sono da morte: um ver dissipado pelo silêncio, a membrana. 
A obra Cy é a realidade que o gesto da arte se dá. Nela, a massa é o que é em si mesma, de modo que o gesto artístico para a qual ela vem-a-ser na obra não é o particular da obra, mas sim a universal massa. No geral, o atuar, e sua efetividade, se transfere para o elemento da universalidade: para o espaço, sem determinacão, do ser arte, massa - e não há uma que não seja, não é? A consciência artística, portanto, se retira da obra, no âmbito do particular, e se entrega à consciência universal da arte, a massa, a membrana.

\section{$\mathbf{X}$}

A obra de $\mathrm{Cy}$ - acontecimento-massa a garantir o acontecimento plástico de um poeta? Ou é o reverso? A pele e o manto, o grafismo e a memória. Quando se chegará ao decidível? Contudo, a matéria está vestida, a massa, um corpo de algo e o corpo mesmo, pois o corpo só é o corpo in memoriam. Será? "Mas Hegel sabia que este corpo próprio e animado do significante era também um túmulo.” (DERRIDA, 1991, p.119). Consagrada está a vida, perseverando-a. Protegida na morte. É assim que se deve entender in memoriam? O monumento funerário é isso, significando o sopro terminado, o verso que aguarda outra respiração, embalsamado, enterrado, protegido, guardado na morte sem morrer. Mas isso já é estrangeiro nesse caso. A alma consignada - retorno da irredutibilidade com o corpo, entre o inteligível e sensível. Imigrante poético, o poeta poético, Álvaro de Campos, irredutível, já ganha alma na obra Cy como presença inteira, na Pirâmide. Esse lugar, que de qualquer modo, como altar sem tempo e ativo, plasma o exercício da arte.

\section{XI}

Pirâmide outra vez? De fato, há algo na obra Cy que não deixa escapar a imagem arcaica da arte. Imagem arcaica, a pirâmide (toda pirâmide é o arqui-princípio de um altar, de uma arquitetura, de uma passagem nada empírica?), é a forma reservada à interioridade da vida, guardada pela morte, e, ao mesmo tempo, a membrana exterior que é o fundo apurado da interioridade mesma - "sentir tudo de todas as maneiras." Relação de absoluta alteridade, digamos assim. A pirâmide põe nos olhos a imagem simples da própria arte, sua desfiguração "a face formal que pertence ao conteúdo verdadeiramente artístico, a saber, a separação quanto à presença imediata." (HEGEL apud DERRIDA, 1991, p. 123). 
À moi, todos os objetos invisíveis de velozes!

Batam-me, trespassem-me, ultrapassem-me!

Sou eu que me bato, que me trespasso, que me ultrapasso!

A raiva de todos os ímpetos fecha em círculo-mim! (CAMPOS, 1964, p. 237).

\section{XII}

A afinidade da morte com a beleza está demarcada na ideia de forma, imposta ao Álvaro, a Cy, e que nela se extinguem e ficam "vivos" na membrana da massa e vice e versa. A beleza da obra Cy reconcilia o inacabado do poema que contém o verso. O inacabado da própria beleza. Pois a vida de um verso, e de uma escultura, e mesmo de uma tumba, de um barco e etc. não é a vida que se assusta ante ao morrer. Se há qualquer coisa como desolação, é porque a vida se desgarra do morrer e se potencializa num cara a cara com a morte, como se fosse a força de uma travessia, fazendo-a vir arte.

Há na obra Cy uma separação da natureza de túmulo, sem poder existir fora da lei que é ele. Ora, o suporte humano do homem é a sepultura — os restos dos suportes é o animal. A obra Cy, porém, implica numa energia monstruosa do verso Álvaro que se opõe à fusão dos elementos de uma sepultura. Ali está o homem separado, cuja beleza não permite a beleza da obra Cy se manifestar sem o seu radical silêncio. Daí provém a experiência da arte que só suporta a morte através dos degraus e daquele grafismo, que lido, suspende o in memoriam e, assim, faz concordar a tumba consigo mesma - "sentir tudo de todas as maneiras", fazer a morte sem nenhum morrer (o novo sempre se aparenta com a morte). Todavia, obra de $\mathrm{Cy}$, ainda, fundamenta e dignifica esse assombro, separando a arte da totalidade dos elementos discerníveis para ditar a memória da morte, a vida, que se agita parente todos que a repelem. Eis o feio a dirimir a ocasião. Ocasião? Que palavra! Do tempo? Assim seja. Seja o quanto pode, não há mão que se perca nessa massa. A morte é o inacabado de tudo - a membrana, a passagem. E a tristeza vai se fazendo e se arrependendo.

Todas as madrugadas são a madrugada e a vida.

Todas as auroras raiam no mesmo lugar:

Infinito...

Todas as alegrias de ave vêm da mesma garganta,

Todos os estremecimentos de folhas são da mesma árvore,

E todos os que se levantam cedo para ir trabalhar

Vão da mesma casa para a mesma fábrica por o mesmo caminho... (Ibid., p. 233). 
Não é a obra a emissária da morte. A morte se assemelha ao processo. Mas isso é por demais óbvio, pois a vida é a membrana que envelopa a morte — se entendemos o que é ser mortal. No impulso singular da obra há o desintegrar da natureza. O seu êxito liberto faz escapar Álvaro como força antagônica de estar vivo nas membranas dos pulmões de outros, nas mãos do outro que é ele mesmo e não é. Contemplado o negativo (negativo?), a obra $\mathrm{Cy}$, frente a frente, conserva o atrelamento com o verso Álvaro, cujo in memoriam realça que a morte nada revela, mantendo o desejo imaginativo da pronúncia do verso, do reverso.

Verso que é, e não é, o lado contrário da obra $\mathrm{Cy}$. Ela por lá no silêncio de quem a vê. $\mathrm{O}$ verso escutado, a vestida arte na obra $\mathrm{Cy}$, sendo o que é: um silêncio liberto de toda forma, ainda a forma - "em lugar de vagamente apelar para a forma, deve-se perguntar o que a forma ela mesma, como conteúdo sedimentado, opera.” (ADORNO, 1992, p.128). Mas o reverso e o verso de todos os dois é qualquer coisa numa coisa só. Apenas o só, essa figura do singular que nem chega a ser figura. $O$ silêncio encantado a traduzir a ambivalência e a dissonância do verso e do seu reverso, o in memoriam. Há de se levar a arte ao absurdo do túmulo, testemunhando o esgotado até empurrá-lo numa unidade indivisível, arte mesma.

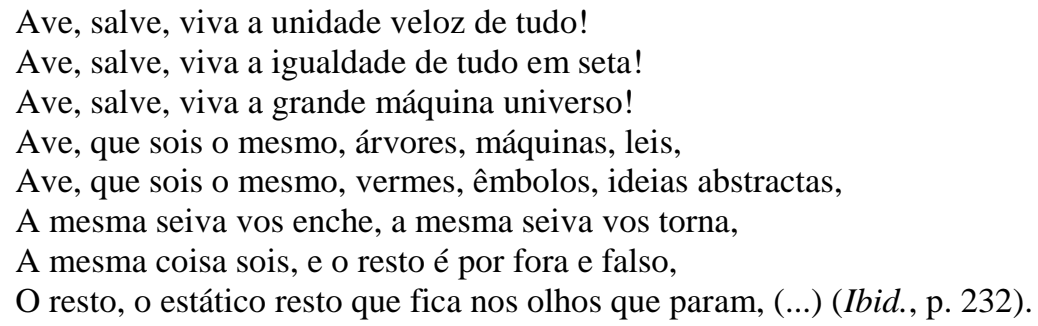

\section{XIV}

Mas tudo desaba nesse instante. Ao olhar a obra $\mathrm{Cy}$, no lado esquerdo de quem a vê, no fundo do segundo degrau à direita, há algumas manchas vermelhas que parecem ter sofrido a tentativa de apagamento. Elas estão ali. Um erro? Um descuido? Uma mão que sangrou? A duras penas? Escorridas manchas. E outra ali. Mas porque? Só mediante ao sacrifício efetivo a arte doa provas da renúncia de si, desvanecendo a fraude que aparece no interior de qualquer ação. Nesse afastar da fraude que reina na ação, a obra de Cy se desprende da infelicidade contida no agir e anseia por um outro da ação. Esse ato é o significado bárbaro da vontade que se consome em si mesma e, ao mesmo tempo, renuncia ao gozo e a posse de algo que já se encontra no "reino animal do espírito (...)” (HEGEL, 2008, p. 277). 
Mas esse sacrifício, da mimese apagada das manchas, com seu gozo, dor, já é um além e um aquém, um ali. Uma luta que vacila entre o conservar e o sacrificar, sendo o que é: ferimento da estranha, a arte. Há reminiscência, deixando que o in memoriam se faça escusa, abandonando a lembrança no houvera sido, e tudo no ponto para não se dizer em dúvida. Mas mesmo assim a obra de Cy confronta-se no sono e na visão. O fim chega. Massa que guarda a antecâmara do nascimento, cuja face da custódia, a membrana, condiz com a sua estada. Massa tumefacta que pede a qualquer um que se apague e não se apegue, que renuncie ao silêncio, silenciando, e viva a desistência, a incompletude, e se mostre verso no reverso da morte, in memoriam — "sentir tudo de todas as maneiras", arte. Não é e é?

\section{Referências}

ADORNO, Theodor W. Parataxis: on Holderlin's Late Poetry. In: Notes to literature. New York: Columbia University Press, 1992.

DERRIDA, Jacques. Margens da Filosofia. São Paulo: Papirus, 1991.

DIDI-HUBERMAN, Georges. O que vemos, O que nos olha. São Paulo: Ed. 34, 1998.

CAMPOS, Álvaro. Poesias de Álvaro de Campos. Lisboa: Edições Ática, 1964.

HEGEL, Georg Wilhelm Friedrich. Fenomenologia do Espírito. Petrópolis: Vozes; Bragança Paulista: Editora Universitária São Francisco, 2008.

\section{Lista de figuras}

Fig.1- Twombly, Cy. sem título ("Em memória de Álvaro de Campos”), 2002. Disponível em: https://www.pinterest.dk/pin/377739487476416134/. Acesso em 30 ago. 2017.

Fig.2- Twombly, Cy. sem título ("Em memória de Álvaro de Campos"), 2002. Disponível em: https://br.pinterest.com/pin/371054456780114602/. Acesso em 30 ago. 2017. 